\title{
Methods for genetic manipulation of Burkholderia gladioli pathovar cocovenenans
}

Nawarat Somprasong ${ }^{1,2}$, lan McMillan², RoxAnn R Karkhoff-Schweizer ${ }^{2}$, Skorn Mongkolsuk', Herbert P Schweizer ${ }^{1,2^{*}}$

\begin{abstract}
Background: Burkholderia gladioli pathovar cocovenenans (BGC) is responsible for sporadic food-poisoning outbreaks with high morbidity and mortality in Asian countries. Little is known about the regulation of virulence factor and toxin production in BGC, and studies in this bacterium have been hampered by lack of genetic tools.

Findings: Establishment of a comprehensive antibiotic susceptibility profile showed that BGC strain ATCC33664 is susceptible to a number of antibiotics including aminoglycosides, carbapenems, fluoroquinolones, tetracyclines and trimethoprim. In this study, we established that gentamicin, kanamycin and trimethoprim are good selection markers for use in BGC. Using a 10 min method for preparation of electrocompetent cells, the bacterium could be transformed by electroporation at high frequencies with replicative plasmids containing the pRO1600-derived origin of replication. These plasmids exhibited a copy number of $>100$ in BGC. When co-conjugated with a transposase expressing helper plasmid, mini-Tn7 vectors inserted site- and orientation-specifically at a single glmS-associated insertion site in the BGC genome. Lastly, a Himar1 transposon was used for random transposon mutagenesis of BGC.
\end{abstract}

Conclusions: A series of genetic tools previously developed for other Gram-negative bacteria was adapted for use in BGC. These tools now facilitate genetic studies of this pathogen and allow establishment of toxin biosynthetic pathways and their genetic regulation.

\section{Background}

Burkholderia gladioli pathovar cocovenenans was first described in the $1960 \mathrm{~s}$ as a bacterium that caused severe cases of food-poisoning and was then named Pseudomonas cocovenenans [1]. It has been re-named several times since. In 1995 the bacterium was named B. cocovenenans $[2,3]$ and in 1999 it was combined with B. gladioli, a phytopathogenic bacterium [4]. Though later analyses confirmed that $B$. cocovenenans and $B$. gladioli should be categorized as a single species, it was deemed necessary to distinguish those strains that are phytogenic from those that also produce toxins lethal to mammals. This resulted in designation of a new pathovar, B. gladioli pathovar cocovenenans (BGC) in 2003 [5].

Outbreaks of severe BGC-caused food-poisoning are sporadic and seem to be confined to Asia. In endemic

\footnotetext{
* Correspondence: herbert.schweizer@colostate.edu

'Department of Biotechnology, Faculty of Science, Mahidol University,

Ratchathewi, Bangkok, Thailand, 10400

Full list of author information is available at the end of the article
}

regions, fermented coconut can be contaminated with BGC, hence the name "cocovenenans". In particular, bacterial derived toxins have been implicated in deaths resulting from eating the soybean and coconut-based product known as tempe bongkrek. Unlike food-poisoning caused by other bacteria, e.g. E. coli $\mathrm{O} 157: \mathrm{H} 7$, mortality rates are significant, reaching $>40 \%$ during an outbreak in China in the 1970's [6,7]. Though temporarily called Flavobacterium farinofermentans [8], it was later shown that this bacterium was identical to P. cocovenenans [9]. Initial symptoms of BGC-caused food-poisoning are evident after a 4-6 hour incubation period and typically include abdominal pains, general malaise, extensive sweating, tiredness and sleepiness, followed by coma. Death usually occurs within 1 to 24 hours after onset of initial symptoms. Diagnosis of the disease is unreliable. This is perhaps best illustrated by a 2007 episode of food-poisoning reported in Central Java (Indonesia)(ProMed Archive numbers 20070802.2439 and 20070806.2557). While this particular episode was first attributed to BGC, this was later doubted and 
attributed to $E$. coli although the symptoms were clearly more consistent with BGC than $E$. coli.

$\mathrm{BGC}$ produces two potent toxins, yellow toxoflavin and colorless bongkrekig acid (BA; also known as bonkrek acid). Though it is not entirely clear whether both toxins contribute to human disease, the evidence points to $\mathrm{BA}$ as the major toxin as other bacteria expressing significant levels of toxoflavin, e.g. the rice pathogen B. glumae, do generally not cause human disease [10]. A crude toxin preparation (basically supernatant of plategrown cells) kills mice within 45 min upon oral administration [5]. Toxoflavin production, its biosynthetic pathways and regulatory mechanisms have been studied at the molecular level in B. glumae [10]. In contrast, very little is known about toxoflavin and BA production in BGC. A single study showed that BA production is stimulated when BGC is grown in the presence of certain unsaturated fatty acids [11]. Molecular studies in BGC are hindered by lack of genetic tools and in this study we extended the arsenal of tools previously developed for P. aeruginosa, B. pseudomallei and other Gram-negative bacteria to BGC.

\section{Results and Discussion}

\section{Determination of antibiotic susceptibility profiles}

As most genetic manipulation methods rely on antibiotic selection, it was paramount to determine the antibiotic susceptibility profile of BGC strain ATCC33664 (Table 1). The findings show that this BGC strain is susceptible to aminoglycosides (e.g. gentamicin, kanamycin and streptomycin), carbapenems (e.g. imipenem and meropenem), fluoroquinolones (e.g. ciprofloxacin and norfloxacin), tetracyclines (e.g. doxycycline and tetracycline) and trimethoprim, but quite resistant to many other antibiotics including many $\beta$-lactams (e.g. ampicillin, amoxicillin, carbenicillin, and ceftazidime), macrolides (e.g. clarithromycin, clindamycin and erythromycin), chloramphenicol, polymyxin B and zeocin. Many cloning and transposon vectors contain aminoglycoside, tetracycline or trimethoprim resistance selection markers and, because of BCG's susceptibility to the respective antibiotics, should thus be applicable in this bacterium.

\section{Transformation by electroporation}

A prerequisite for any genetic manipulation is the ability to deliver exogenous DNA, e.g. plasmids, into the targeted host strain. The two most commonly used methods are electroporation or conjugation. We previously developed a rapid method for preparation of electrocompetent $P$. aeruginosa cells [12] which was subsequently adapted for use in B. pseudomallei [13]. We therefore tested the method in BGC strain ATCC33664. Using the standard method detailed in the Methods
Table 1 Antibiotic susceptibilities of BGC strain ATCC33664

\begin{tabular}{|c|c|}
\hline Antibiotic & $\mathrm{MIC}(\mu \mathrm{g} / \mathrm{ml})$ \\
\hline Ampicillin & 64 \\
\hline Amoxicillin & 256 \\
\hline Carbenicillin & 64 \\
\hline Ceftazidime & 32 \\
\hline Imipenem & 4 \\
\hline Meropenem & 0.75 \\
\hline Ciprofloxacin & 0.5 \\
\hline Norfloxacin & 8 \\
\hline Clindamycin & $>1024$ \\
\hline Clarithromycin & 128 \\
\hline Erythromycin & 128 \\
\hline Gentamicin & 0.125 \\
\hline Kanamycin & 0.25 \\
\hline Streptomycin & 8 \\
\hline Doxycycline & 4 \\
\hline Tetracycline & 8 \\
\hline Trimethoprim & 0.125 \\
\hline Polymyxin B & $>1024$ \\
\hline Zeocin & 256 \\
\hline
\end{tabular}

Antibiotic susceptibilities were either determined using E-test (imipenem, meropenem and trimethoprim) or the two-fold serial microdilution method (all others).

section, this strain was subjected to electrotransformation with pUCP28T or pUCP30T. These and other plasmids based on the pRO1600 replicon were previously shown to replicate in other Burkholderia species [13,14]. Selection on LB plates containing $100 \mu \mathrm{g} / \mathrm{ml}$ trimethoprim (pUCP28T) or $30 \mu \mathrm{g} / \mathrm{ml}$ gentamicin (pUCP30T) by incubation for two days at $30^{\circ} \mathrm{C}$ resulted in a transformation efficiency of $10^{6}$ and $10^{7}$ colony forming units/ $\mu \mathrm{g}$ of input DNA which is comparable to efficiencies seen with $P$. aeruginosa [12]. The copy number of pUCP30T in log phase BGC strain ATCC33664 cells growing in LB medium was $>100$ as determined by using a previously described quantitative real-time PCR method [13,15]. This is in contrast to B. pseudomallei where the copy number of pRO1600 replicon-containing plasmids was determined to be 3-4 [13]. The results indicated that pUCP28T and pUCP30T can efficiently be transformed into BGC, replicate in this bacterium at a fairly high copy number and can thus be used to overexpress genes cloned into these plasmid vectors.

\section{Application of the mini-Tn7 system in BGC}

Transposon Tn7 based mini-Tn7 vectors exhibit several features distinct from plasmid vectors: 1) they integrate into the chromosome site- and orientation-specifically and are thus maintained in single-copy; 2) because they 
replicate along with the chromosome they are stable and only require antibiotic selection for initial selection of the transposition event; 3 ) they are broad-host-range and their use is only limited by availability of delivery vehicle transfer method (electroporation or conjugation) and selection marker; and 4) detailed methods for transposon delivery and integration site mapping have been described [16-19].

To assess the utility of mini- $\operatorname{Tn} 7$ based vectors in BGC, the helper plasmid pTNS3 [13] and the mini-Tn7 delivery vector pUC18T-mini-Tn7T-Gm-REP [18] were transformed into E. coli mobilizer strain $\mathrm{RHO} 3$ and conjugations with BGC performed as previously described [20]. Co-conjugation of both helper and delivery plasmids into BGC strain ATCC33664 followed by selection on LB agar plates containing $30 \mu \mathrm{g} / \mathrm{ml}$ gentamicin resulted in numerous gentamicin resistant transformants after incubation at $30^{\circ} \mathrm{C}$ for two days. Because BGC's genome sequence is unknown, we used a previously described method for mapping the Tn7 insertion site(s) [17] as detailed in the methods section. Sequencing of DNA flanking the transposon left and rights ends revealed that the insertions occurred either between nucleotides 24 and 25 or 25 and 26 downstream of a putative $g \operatorname{lm} S$ gene (Figure 1). This insertion site and distance from $g \operatorname{lm} S$ is consistent with what has been observed in other bacteria as mini- $\mathrm{Tn} 7$ elements almost always insert downstream of $g l m S$, although rare exceptions do exist [19]. This insertion site was verified in six distinct gentamicin resistant transformants using the

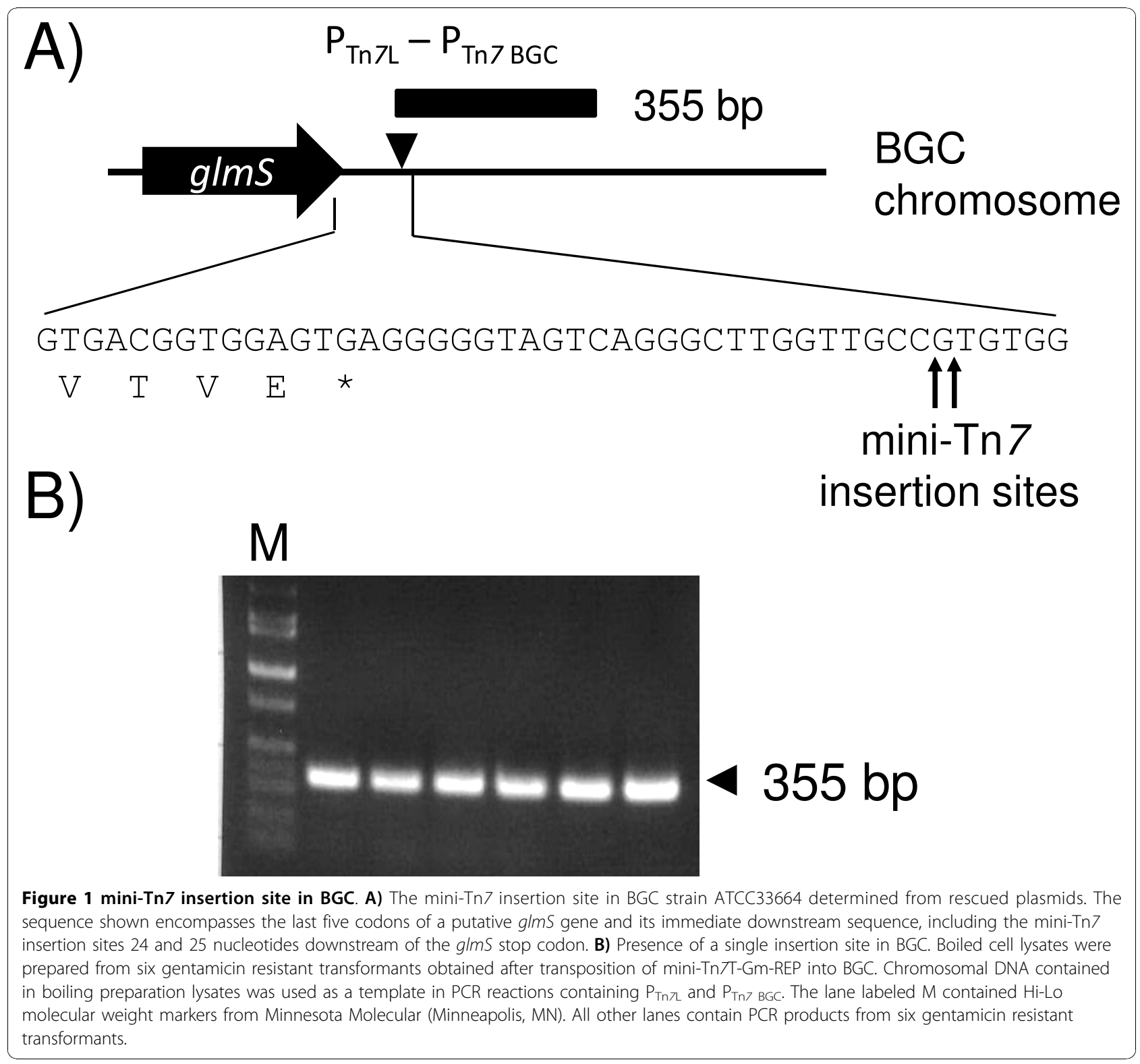


BGC-specific primer $\left(\mathrm{P}_{\mathrm{Tn} 7-\mathrm{BGC}}\right)$ and a primer annealing to the transposon left end $\left(\mathrm{P}_{\mathrm{Tn} 7 \mathrm{~L}}\right)$ (Figure 1$)$. The expected 355 bp PCR fragment was observed in all six transformants and sequencing confirmed the expected Tn 7 insertion sites either after nucleotide 24 or 25 downstream of the $\mathrm{glmS}$ stop codon. Since all Burkholderia species analyzed to date contained multiple $\mathrm{glmS}$ genes and thus multiple mini-Tn7 insertion sites $[13,16,17]$, boiling lysates were prepared from 90 gentamicin resistant transformants and used as templates in PCR reactions with $\mathrm{P}_{\mathrm{Tn} 7-\mathrm{BGC}}$ and $\mathrm{P}_{\mathrm{Tn} 7 \mathrm{~L}}$. Observation of the same PCR fragment in all tested transformants indicated a single mini-Tn7 insertion site in BGC (data not shown). We were unable to obtain gentamicin resistant transformants in a second transposition event using a strain with an existing insertion at the $g \operatorname{lm} S$-associated site but having the gentamicin resistance marker deleted by site-specific recombination using Flp recombinase. The overall experimental evidence corroborates the notion of BGC having only one glmS-associated miniTn7 insertion site which can be used for efficient, sitespecific insertion of mini-Tn7 elements.

\section{Flp recombinase-mediated marker excision from chromosomally-inserted DNA}

Site-specific recombinases, usually yeast Flp recombinase or bacteriophage P1 Cre recombinase, can be used for site-specific excision (deletion) of DNA fragments flanked by the cognate recombination sites, i.e. Flp recombinase target (FRT) sites for Flp or loxP sites for Cre [21]. We previously demonstrated use of Flp and Cre recombinases in various bacteria, including B. pseudomallei, for derivation of markerless mutants $[13,22]$.

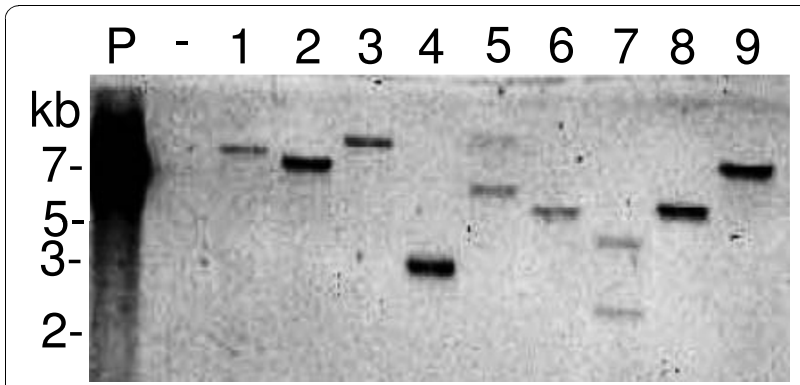

Figure 2 Random transposition of Himar1 in BGC. Genomic DNA was prepared from nine randomly selected kanamycin resistant transformants, digested for $3 \mathrm{~h}$ with Notl, and transferred to a nylon membrane. The membrane was hybridized with a probe that detected ori R6K $_{\text {on }}$ the transposon. DNA from BGC strain ATCC33664 was included as a negative control (lane -). The positive control (lane P) was pHBurk3. The 7-, 5-, 3- and 2-kb fragments contained in the biotinylated 2-log DNA ladder (New England Bio-Labs) are indicated on the left. The two hybridizing fragments observed in lanes 5 and 7 are indicative of double Himar 1 insertions in the respective mutants.
Excision of antibiotic selection markers allows recycling of the same resistance determinants in subsequent genetic manipulation procedures. To assess efficiency of Flp recombinase mediated marker excision, we transformed the Flp expression plasmid pFLPe4 into a gentamicin resistant $\mathrm{BGC}$ strain containing a chromosomally integrated mini-Tn7T-Gm-REP element. On this plasmid, expression of the enhanced Flp structural gene is under control of a rhamnose-regulated promoter [13]. When transformants were plated on LB plates containing $35 \mu \mathrm{g} / \mathrm{ml}$ kanamycin and $0.2 \%$ rhamnose, the gentamicin marker was efficiently excised (all kanamycin resistant transformants were gentamicin susceptible). Furthermore, pFLPe4 was rapidly cured from cells grown at $37^{\circ} \mathrm{C}$ indicating the temperature-sensitive origin of replication contained on this plasmid is functioning at permissive temperature $\left(30^{\circ} \mathrm{C}\right)$ but not the non-permissive $\left(37^{\circ} \mathrm{C}\right)$ temperature. We conclude that site-specific recombinases can be used in BGC for efficient excision of antibiotic resistance markers from chromosomally integrated DNA elements. Although we have not yet tried Cre recombinase it can be assumed that the Cre/loxP system will function in BGC as well.

\section{Himar1 random mutagenesis}

Random transposon mutagenesis is a powerful tool for generation of mutants useful for pathogenesis and other studies. We previously described an efficient in vivo Himar1 transposon mutagenesis system for B. pseudomallei and demonstrated its use for the isolation of auxotrophic and other mutants [23]. Mariner-based transposons function in many bacteria since they do not require host-specific factors and, other than preference for a TA dinucleotide target, do not display target site specificity. To assess the utility of Himarl transposition system in BGC, we transformed pHBurk3 [23] into strain ATCC33664 by electroporation and selected kanamycin resistant transformants at $37^{\circ} \mathrm{C}$. At this temperature, pHBurk3 does not replicate and kanamycin resistant colonies should only arise by transposition of the Himar1 transposon into chromosomal DNA. Electroporation of $300 \mathrm{ng}$ of pHBurk3 into BGC ATCC33664 yielded $1.6 \times 10^{4}$ kanamycin resistant colonies at the non-permissive temperature $\left(37^{\circ} \mathrm{C}\right)$ and $3.6 \times$ $10^{4}$ kanamycin resistant colonies at the permissive temperature $\left(30^{\circ} \mathrm{C}\right)$. The calculated rate of transposition is therefore $44 \%$, similar to what has been observed with B. pseudomallei [23]. Twenty kanamycin resistant colonies were picked, chromosomal DNA isolated and subjected to genomic Southern analysis using a transposonspecific probe. An analysis of chromosomal DNA from nine colonies is shown in Figure 2. It is evident that the Himar1 transposon inserts randomly in chromosomal DNA and there is a low propensity for double 
insertions. Of a total of 20 colonies analyzed, only three had double insertions (two of them were included in Figure 2, lanes 5 and 7). A preliminary analysis of $\sim 1,700$ mutants by replica plating on M9 glucose minimal medium showed a surprisingly low $(0.12 \%)$ auxotrophy rate. This compares to a rate of $0.72 \%$ observed for B. pseudomallei [23]. Because the Himar1 transposon located on pHBurk3 contains an R6K origin of replication and a kanamycin resistance selection marker, selfligation of chromosomal DNA fragments obtained by digestion with a restriction enzyme that does not cleave transposon DNA allows rescue of replicating plasmids after transformation of an $E$. coli strain expressing the $\pi$ protein. Plasmid rescue was performed from one of the auxotrophic mutants and DNA sequencing revealed that the insertion occurred within the amidophosphoribosyltransferase structural gene purF. Nutritional supplementation experiments with adenine restored growth of the mutant on M9 glucose minimal medium and supported the functional assignment of purF within the de novo purine biosynthetic pathway. The experimental evidence shows that the Himarl transposon can be used in BGC for generation of random chromosomal mutations.

\section{Conclusions}

We have shown that many of the tools previously developed for other Burkholderia species function efficiently in BGC and can thus be used for genetic manipulation of this bacterium, and probably the closely related phytopathogenic B. gladioli. Determination of the antibiotic susceptibility profiles indicated that aminoglycosides (gentamicin and kanamycin) as well as trimethoprim resistance markers provide a clean selection in BGC using relatively low antibiotic levels. This was initially demonstrated by successful electroporation of two replicative plasmids, pUCP28T and pUCP30T, using a rapid, microcentrifuge-based procedure for preparation of electrocompetent cells. Co-conjugation of a helper and delivery plasmid from $E$. coli to BGC showed that mini$\mathrm{Tn} 7$ elements can be readily transposed into the BGC genome. Unlike other Burkholderia species, BGC seems to contain only one glmS-linked insertion site. Transposition events can readily be monitored by developments of a BGC-specific primer and defined PCR conditions. Site-specific excision of the gentamicin resistance marker from the chromosomally-integrated mini-Tn7 element using Flp recombinase proved the functionality of the Flp/FRT system for marker excision in BGC and rapid curing of the Flp expression plasmid at non-permissive temperature. Lastly, we established that the mariner based Himar1 transposon can be used for rapid, random mutagenesis of the BGC genome. The tools and methods described here provide the basis for genetic manipulation and modification of BGC, something that was to date unachievable. The authors realize that the conclusions relating to the applicability of the methods to the species are based on a single isolate. However, a limited number of BGC strains are available and it is likely that most studies will be performed using the type strain, ATCC33664, used in this study.

\section{Methods}

\section{Bacterial strains, media and growth conditions}

B. gladioli pathovar cocovenenans (BGC) ATCC33664 was obtained from the American Type Culture Collection, Manassas, VA. E. coli strains used were DH5 $\alpha$ ( $\lambda$ pir)(laboratory collection) and RHO3 [20]. RHO3 is a $\Delta$ asd mutant and requires $400 \mu \mathrm{g} / \mathrm{ml}$ diaminopimelic acid (DAP; LL-, DD-, and meso-isomers; Sigma, St. Louis, MO) for growth on rich media. Bacteria were routinely grown at $37^{\circ} \mathrm{C}($ E. coli $)$ or $30^{\circ} \mathrm{C}(\mathrm{BGC})$ in Luria broth Lennox (LB) [24] or on LB agar purchased from MO BIO Laboratories, Carlsbad, CA. Strains containing temperature-sensitive (TS) plasmid derivatives or TS alleles were grown at $30^{\circ} \mathrm{C}$ (permissive temperature) or $37^{\circ} \mathrm{C}$ (non-permissive temperature). M9 medium [25] with $10 \mathrm{mM}$ glucose was used as the minimal medium and supplemented with $0.6 \mathrm{mM}$ adenine to support growth of purF mutants. Antibiotics were added at the following concentrations: $100 \mu \mathrm{g} / \mathrm{ml}$ ampicillin, $15 \mu \mathrm{g} /$ $\mathrm{ml}$ gentamicin and $35 \mu \mathrm{g} / \mathrm{ml}$ kanamycin for E. coli; $15-$ $30 \mu \mathrm{g} / \mathrm{ml}$ gentamicin and $35 \mu \mathrm{g} / \mathrm{ml}$ kanamycin for BGC. Minimal inhibitory concentrations (MICs) were determined in Mueller-Hinton broth (Becton Dickinson, Franklin Lakes, NJ) by the 2-fold broth microdilution technique following Clinical and Laboratory Standards Institute guidelines [26]. The MICs were recorded after incubation at $30^{\circ} \mathrm{C}$ for $24 \mathrm{~h}$. Antibiotics were purchased from the following manufacturers: carbenicillin was from Duchefa Biochemie via Gold Biotechnology, St. Louis, MO; ciprofloxacin was from LKT Laboratories, St. Paul, MN; gentamicin was from EMD Biosciences, San Diego; zeocin was from Invitrogen, Carlsbad, CA; and all others were from Sigma, St. Louis, MO.

\section{DNA and genetic methods}

Details of most of the methods described herein have previously been described and adapted for use in BGC with minor modifications.

\section{Plasmids}

Plasmid DNAs were isolated from E. coli and Burkholderia spp. by using a Fermentas GeneJET Plasmid MiniPrep Kit (Fermentas, Glen Burnie, MD). Plasmids used in this study included the replicative pUCP28T [14], pUCP30T [14] and pFLPe4 [13]. The non-replicative plasmids pTNS3 [13], pUC18T-mini-Tn7T-Gm-REP 
[18] and pHBurk3 [23] were used as sources for the Tn7 site-specific transposition pathway, mini-Tn7T-Gm-REP, and Himar1 transposon, respectively. The GenBank accession numbers for plasmids are U33751 for pUCP28T; U33752 for pUCP30T; EU215438 for pFLPe4; EU215432 for pTNS3; AY712952 for pUC18Tmini-Tn7T-Gm-REP and EU919403 for pHBurk3.

\section{Electrocompetent cells, transformation and plasmid copy number}

Bacterial cells were made competent by a rapid method [12]. Briefly, cells were grown overnight at $30^{\circ} \mathrm{C}$ and $1 \mathrm{ml}$ of this culture was harvested by centrifugation in a microfuge at 8,000 rpm for $2 \mathrm{~min}$. The cells were washed twice with $1 \mathrm{ml}$ of sterile $300 \mathrm{mM}$ sucrose by resuspension with a pipet tip and centrifugation at $8,000 \mathrm{rpm}$ for $2 \mathrm{~min}$. Cells were finally resuspended in 100-200 $\mu \mathrm{l}$ of $300 \mathrm{mM}$ sucrose. All solutions and manipulation steps were at room temperature. One hundred microliter aliquots of electrocompetent cells were then used in electroporation experiments using previously described conditions, except that after electroporation cells were incubated at $30^{\circ} \mathrm{C}$ for $1 \mathrm{~h}$ prior to plating on selective media. BGC cells were typically transformed with 100 to 200 ng of plasmid DNA. A quantitative real-time PCR method was used for determination of plasmid copy number in BGC $[13,15]$. With this method, the separate detections of a plasmid and host chromosomal DNA were achieved using two separate primer sets, specific for the plasmid aminoglycoside resistance gene $(a a c C I)$ and for the chromosomal, single-copy aspartate- $\beta$-semialdehyde dehydrogenase gene (asd). Primers were designed using Primer 3 software and were as follows: for aacC1, aacC1-Q-F (5'-CTGATGTTGGGAGTAGGTG) and aacC1-Q-R (5'-GTTAGGTGGCTCAAGTATGG), yielding an 130-bp product; and for asd, asd-RT-UP (5-ACACGTCGTTCGTGTAGTCG) and asd-RT-DN (5 AAAACGAGACCACGCTCAAG), yielding a 99-bp product. Real-time quantitative PCR amplifications of the total DNA samples from two separate BCG ATCC33664 cultures harboring pUCP30T were performed. The absolute copy numbers of $a a c C 1$ and asd genes in the BGC total DNA samples were determined from the respective standard curves, using the threshold cycle values. The plasmid copy numbers of pUCP30T was calculated by dividing the absolute copy number of aac $\mathrm{C} 1$ by the copy number of asd. Experiments were repeated three times for calculation of copy number.

\section{Transposition of mini-Tn7 and determination of insertion site}

The helper plasmid pTNS3 [13] and the mini-Tn7 delivery vector pUC18T-mini-Tn7T-Gm-REP [18] were transformed into E. coli mobilizer strain RHO3 [20].
Co-conjugation of both helper and delivery plasmids into BCG strain ATCC33664 was achieved by triparental mating. E. coli and BGC cultures were grown overnight at $37^{\circ} \mathrm{C}$ or $30^{\circ} \mathrm{C}$, respectively. $200 \mu \mathrm{l}$ of each culture was transferred to the same microcentrifuge tube and cells harvested by centrifugation at $8,000 \mathrm{rpm}$ at room temperature. Cells were washed twice with LB medium and then resuspended in $30 \mu \mathrm{l}$ of LB. The cell suspension was transferred to a filter sitting on an LB agar plate containing $400 \mu \mathrm{g} / \mathrm{ml} \mathrm{DAP.} \mathrm{After} \mathrm{overnight} \mathrm{incubation}$ at $30^{\circ} \mathrm{C}$, the filter was transferred to a microcentrifuge tube containing $1 \mathrm{ml}$ of LB and cells dislodged by vortexing for $60 \mathrm{~s}$. Aliquots $(50$ and $100 \mu \mathrm{l})$ were spread on LB-agar plates with $30 \mu \mathrm{g} / \mathrm{ml}$ gentamicin and plates incubated at $30^{\circ} \mathrm{C}$ for two days. For insertion site mapping, we used a previously described method [17]. Briefly, six gentamicin resistant transformants were grown overnight in LB medium with $30 \mu \mathrm{g} / \mathrm{ml}$ gentamicin and genomic DNA was isolated using a PUREGENE genomic DNA purification kit (Gentra Systems, Minneapolis, MN). $1 \mu \mathrm{g}$ of this DNA was then digested with Not $\mathrm{I}$ for $2 \mathrm{~h}$ and the resulting DNA fragments were selfligated overnight at $14^{\circ} \mathrm{C}$. The ligation mixtures were transformed into DH5 $\alpha$ ( $\lambda$ pir) and gentamicin resistant transformants selected by plating on LB medium with $15 \mu \mathrm{g} / \mathrm{ml}$ gentamicin. Plasmid DNA was then isolated from transformants grown in LB medium with $15 \mu \mathrm{g} / \mathrm{ml}$ gentamicin and sequenced using either $\mathrm{P}_{\mathrm{Tn} 7 \mathrm{~L}}$ or $\mathrm{P}_{\mathrm{Tn} 7 \mathrm{R}}$ as a primer. After insertion site mapping, a BGC-specific primer ( $\mathrm{P}_{\mathrm{Tn} 7-\mathrm{BGC}} ; 5$ '-GGAACAGGCTGAAACGAGAG) was used in conjunction with $\mathrm{P}_{\mathrm{Tn} \pi}$ (5'-ATTAGCTTACGACGCTACACCC;[18]) to rapidly identify transformants with mini- $\operatorname{Tn} 7$ insertions at this $g \operatorname{lm} S$-associated site by colony PCR using DNA in boiling preparation lysates as templates. These lysates were obtained by transferring separate colonies to individual sterile microcentrifuge tubes containing $30 \mu \mathrm{l}$ of sterile $\mathrm{H}_{2} \mathrm{O}$ and boiling for $5 \mathrm{~min}$. Insertions at this site are characterized by amplification of a 355 bp DNA fragment (Figure 1B).

\section{Flp mediated excision of antibiotic selection markers and curing of expression plasmid}

Flp-mediated excision of chromosomally inserted gentamicin resistance markers was achieved using previously described procedures and pFLPe4 [13]. Briefly, cells were transformed with $150 \mathrm{ng}$ pFLPe4 DNA and kanamycin resistant cells selected at $30^{\circ} \mathrm{C}$ on $\mathrm{LB}$ plates with $35 \mu \mathrm{g} / \mathrm{ml}$ kanamycin and $0.2 \%$ rhamnose to promote FLP gene expression. Kanamycin resistant transformants were struck for single colonies onto the same selective plates and colonies were then patched on LB and LB + $30 \mu \mathrm{g} / \mathrm{ml}$ gentamicin plates, followed by incubation at $30^{\circ} \mathrm{C}$. Gentamicin susceptible colonies indicate successful excision of the gentamicin resistance marker. For 
curing of pFLPe4, a gentamicin susceptible colony was inoculated into LB medium and grown overnight at $30^{\circ} \mathrm{C}$. Cells from this culture were then struck onto LB agar plates for single colonies and the plates incubated at $37^{\circ} \mathrm{C}$. Single colonies growing on these plates were then patched onto $\mathrm{LB}, \mathrm{LB}+30 \mu \mathrm{g} / \mathrm{ml}$ gentamicin and $\mathrm{LB}+35 \mu \mathrm{g} / \mathrm{ml}$ kanamycin plates. Cells growing only on the LB plates were saved.

\section{Himar1 transposition into BCG and insertion site mapping} pHBurk3 is a Himar1 delivery plasmid with a temperature sensitive origin of replication, a Himar1 transposon containing a kanamycin resistance selection marker and an R6K-derived origin of replication [23]. For transposition into BGC, electrocompetent cells of strain ATCC33664 were transformed with 300 ng of pHBurk3 DNA and kanamycin resistant colonies selected at $37^{\circ} \mathrm{C}$ on LB plates containing $35 \mu \mathrm{g} / \mathrm{ml}$ kanamycin. Kanamycin resistant colonies growing at this temperature represent cells containing chromosomally inserted Himar1 transposons. For genomic Southern analysis, 20 kanamycin resistant colonies were picked, grown overnight in LB medium with $35 \mu \mathrm{g} / \mathrm{ml}$ kanamycin and genomic DNA isolated with the Gentra PUREGENE DNA purification kit. DNA $(2 \mu \mathrm{g})$ was digested with NotI for $3 \mathrm{~h}$, electrophoresed on a $1 \%$ agarose gel, and transferred to positively charged nylon membranes (Roche Diagnostics Corp., Indianapolis, IN) by passive transfer as previously described (23). Following transfer and UV fixation, blots were probed with a PCR fragment biotinylated by random hexamer priming following the NEBlot Phototype labeling and detection kit protocols (New England BioLabs, Beverly, MA). The probe detected the HimarBP transposon with a 376-bp fragment recognizing the ori $_{\text {R6K }}$ region.

\section{Acknowledgements \\ NS was supported by a Royal Golden Jubilee predoctoral fellowship from the Thailand Research Foundation. We thank Marissa Castillo for assisting with antimicrobial susceptibility assays. This research was supported by indirect cost recovery funds made possible by several NIH research grants awarded to HPS}

\section{Author details}

'Department of Biotechnology, Faculty of Science, Mahidol University, Ratchathewi, Bangkok, Thailand, 10400. '2Department of Microbiology, Immunology and Pathology, Colorado State University, IDRC at Foothills Campus, 0922 Campus Delivery, Fort Collins, CO 80523, USA.

\section{Authors' contributions}

NS performed most of the experiments, IM determined plasmid copy numbers, RKS designed and supervised experiments, SM participated in student supervision, and HPS designed and supervised experiments and drafted the final manuscript. All authors read and approved the final manuscript.

\section{Competing interests}

The authors declare that they have no competing interests.
Received: 24 August 2010 Accepted: 16 November 2010 Published: 16 November 2010

\section{References}

1. vanDamme PA, Johannes AG, Cox HC, Berends W: On toxoflavin, the yellow poison of Pseudomonas cocovenenans. Red Trav Chim Pays-Bas Belg 1960, 79:255-267.

2. Gillis M, Van T, Bardin R, Goor M, Hebbar P, Willems A, Segers P, Kersters $K$ Heulin T, Fernandez MP: Polyphasic taxonomy in the genus Burkholderia leading to an amended description of the genus and proposition of Burkholderia vietnamensis sp. nov. for $\mathrm{N}_{2}$-fixing isolates from rice from Vietnam. Int J Syst Bacteriol 1995, 45:274-289.

3. Zhao N, Qu C, Wang E, Chen W: Phylogenetic evidence for the transfer of Pseudomonas cocovenenans (van Damme et al. 1960) to the genus Burkholderia as Burkholderia cocovenenans (van Damme et al. 1960) comb. nov. Int J Syst Bacteriol 1995, 45:600-603.

4. Coenye T, Holmes B, Kersters K, Govan JR, Vandamme P: Burkholderia cocovenenans (van Damme et al. 1960) Gillis et al. 1995 and Burkholderia vandii Urakami et al. 1994 are junior synonyms of Burkholderia gladioli (Severini 1913) Yabuuchi et al. 1993 and Burkholderia plantarii (Azegami et al. 1987) Urakami et al. 1994, respectively. Int J Syst Bacteriol 1999, 49(Pt 1):37-42

5. Jiao Z, Kawamura Y, Mishima N, Yang R, Li N, Liu X, Ezaki T: Need to differentiate lethal toxin-producing strains of Burkholderia gladioli, which cause severe food poisoning: description of B. gladioli pathovar cocovenenans and an emended description of B. gladioli. Microbiol Immunol 2003, 47:915-925.

6. Meng $Z$, Li Z, Jin J, Zhang $Y$, Liu $X$, Yiang $X$, Ren H: Studies on fermented corn flour poisoning in rural areas of China. I. Epidemiology, Clinical Manifestations, and Pathology. Biomed Environ Sci 1988, 101-104.

7. Meng Z, Wang D, Li Z, Jin J, Bai J, Zhang Y, Liu X, Cai L, Li X, Ren H, et al: Studies on fermented corn flour food poisoning in rural areas of China. II. Isolation and identification of causal microorganisms. Biomed Environ Sci 1988, 1:105-114.

8. Meng Z, Su CH, Li CP, Li K, Liu YQ, Liu Y, Yong YM, Wang PF, Wang YH, Chen JS: Comparing studies on Flavobacterium farinofermentans sp. nov. (tentative name) and Pseudomonas cocovenenans (NCIB9450). J Hyg Res 1987, 16:17-22, (in Chinese).

9. Zhao NX, Ma MS, Zhang YP, Xu DC: Comparative description of Pseudomonas cocovenenans (van Damme, Johannes, Cox, and Berends 1960) NCIB 9450T and strains isolated from cases of food poisoning caused by consumption of fermented corn flour in China. Int J Syst Bacteriol 1990, 40:452-455.

10. Kim J, Kim JG, Kang Y, Jang JY, Jog GJ, Lim JY, Kim S, Suga H, Nagamatsu T, Hwang I: Quorum sensing and the LysR-type transcriptional activator ToxR regulate toxoflavin biosynthesis and transport in Burkholderia glumae. Mol Microbiol 2004, 54:921-934.

11. Garcia RA, Hotchkiss JH, Steinkraus KH: The effect of lipids on bongkrekic (Bongkrek) acid toxin production by Burkholderia cocovenenans in coconut media. Food Addi Conta 1999, 16:63-69.

12. Choi K-H, Kumar A, Schweizer HP: A 10 min method for preparation of highly electrocompetent Pseudomonas aeruginosa cells: application for DNA fragment transfer between chromosomes and plasmid transformation. J Microbiol Methods 2006, 64:391-397.

13. Choi K-H, Mima T, Casart Y, Rholl D, Kumar A, Beacham IR, Schweizer HP: Genetic tools for select agent compliant manipulation of Burkholderia pseudomallei. Appl Env Microbiol 2008, 74:1064-1075.

14. Schweizer HP, Klassen TR, Hoang T: Improved methods for gene analysis and expression in Pseudomonas. In Molecular Biology of Pseudomonads. Edited by: Nakazawa T, Furukawa K, Haas D, Silver S. Washington, D.C.: ASM Press; 1996:229-237.

15. Lee C, Kim J, Shin SG, Hwang S: Absolute and relative QPCR quantification of plasmid copy number in Escherichia coli. J Biotechnol 2006, 123:273-280.

16. Choi K-H, Gaynor JB, White KG, Lopez C, Bosio CM, Karkhoff-Schweizer RR, Schweizer HP: A Tn7-based broad-range bacterial cloning and expression system. Nat Methods 2005, 2:443-448.

17. Choi K-H, DeShazer D, Schweizer HP: mini-Tn7 insertion in bacteria with multiple glmS-linked attTn7 sites: example Burkholderia mallei ATCC 23344. Nat Protocols 2006, 1:162-169. 
18. Choi K-H, Schweizer HP: mini-Tn7 insertion in bacteria with single attTn7 sites: example Pseudomonas aeruginosa. Nat Protocols 2006, 1:153-161.

19. Choi K-H, Schweizer HP: mini-Tn7 insertion in bacteria with secondary, non-glmS-linked attTn7 sites: example Proteus mirabilis HI4320. Nat Protocols 2006, 1:170-178.

20. Lopez CM, Rholl DA, Trunck LA, Schweizer HP: Versatile dual-technology system for markerless allele replacement in Burkholderia pseudomallei. Appl Environ Microbiol 2009, 75:6496-6503.

21. Schweizer HP: Applications of the Saccharomyces cerevisiae Flp/FRT system in bacterial genetics. J Mol Microbiol Biotechnol 2003, 5:67-77.

22. Hoang TT, Karkhoff-Schweizer RR, Kutchma AJ, Schweizer HP: A broad-hostrange Flp-FRT recombination system for site-specific excision of chromosomally-located DNA sequences: application for isolation of unmarked Pseudomonas aeruginosa mutants. Gene 1998, 212:77-86.

23. Rholl DA, Trunck LA, Schweizer HP: Himar1 in vivo Transposon Mutagenesis of Burkholderia pseudomallei. Appl Environ Microbiol 2008, 74:7529-7535.

24. Sezonov G, Joseleau-Petit D, D'Ari R: Escherichia coli physiology in LuriaBertani broth. J Bacteriol 2007, 189:8746-8749.

25. Miller JH: A Short Course in Bacterial Genetics. Cold Spring Harbor, N.Y: Cold Spring Harbor Laboratory Press; 1992.

26. Clinical and Laboratory Standards Institute: M7-A7, Methods for dilution antimicrobial susceptibility tests for bacteria that grow aerobically; approved standard. Wayne, $\mathrm{PA}_{i}$ s seventh 2006.

doi:10.1186/1756-0500-3-308

Cite this article as: Somprasong et al: Methods for genetic manipulation of Burkholderia gladioli pathovar cocovenenans. BMC Research Notes 2010 3:308.

\section{Submit your next manuscript to BioMed Central and take full advantage of:}

- Convenient online submission

- Thorough peer review

- No space constraints or color figure charges

- Immediate publication on acceptance

- Inclusion in PubMed, CAS, Scopus and Google Scholar

- Research which is freely available for redistribution

Submit your manuscript at www.biomedcentral.com/submit 